\title{
Comparison of different methods for release of Bifidobacterium longum Bb46 from the poly(vinylpyrrolidone)-poly(vinylacetate-co-crotonic acid (PVP:PVAc-CA) interpolymer complex matrix, and the effect of grinding on the microparticles
}

\author{
Thantsha M.S. ${ }^{1 *}$, Guest $\mathbf{J}^{1}$ and Mputle $\mathbf{I}^{2}$ \\ ${ }^{1}$ Department of Microbiology and Plant Pathology, New Agricultural building, University of Pretoria, Pretoria, \\ 0002, South Africa \\ ${ }^{2}$ Polymers, Ceramics and Composites, Council for Scientific and Industrial Research (CSIR), Pretoria, South Africa \\ *Corresponding author: Tel: +2712 420 4562, Fax: +2712 420 3266; E-mail:mapitsi.thantsha@up.ac.za
}

\begin{abstract}
Bifidobacteria have been efficiently encapsulated in poly(vinylpyrrolidone)-poly(vinylacetate-co-crotonic acid) (PVP:PVAc-CA) interpolymer complex formed in $\mathrm{scCO}_{2}$. Research indicated that this method improves the stability of encapsulated bacteria in simulated gastrointestinal fluids in vitro. However, further analysis indicated release of lower numbers of encapsulated bacteria from the encapsulating matrix. The aims of this study were to determine a method that would release high numbers of bacteria from the PVP:PVAc-CA interpolymer complex matrix microparticles, and furthermore, to determine the effects of milling on the morphological properties of the microparticles. Three release methods, namely sonication, homogenization in a stomacher and incubation in simulated intestinal fluid (SIF) were compared. Released viable bacteria were assayed using plate counts. Viable bacteria released using a stomacher were three orders of magnitude higher than those released by incubation and an order of magnitude higher than those released using sonication. SEM indicated no negative effects such as exposure of encapsulated bacteria on the matrix due to milling of product. Homogenization in a stomacher is the most efficient method for releasing bacteria from the PVP:PVAc-CA interpolymer complex matrix. Particle size of the PVP:PVAc-CA microparticles encapsulating bacteria can be reduced further by grinding, without exposing the enclosed bacteria.
\end{abstract}

Keywords: encapsulation; sonication; stomacher; interpolymer complex; poly(vinylpyrrolidone)-poly(vinylacetateco-crotonic acid 


\section{Introduction}

Microencapsulation is a method that has been recently explored for protection of probiotics from detrimental environmental conditions such as acidic gastric fluids and exposure to oxygen during storage (Krasaekoopt et al 2003). Several methods have been developed and the majority showed a very good potential for fulfilling this much desired purpose in terms of functionality of probiotics. Encapsulation of probiotics in an interpolymer complex matrix formed in supercritical carbon dioxide is one of the methods that have been recently developed (Moolman et al 2006).

In order to analyze the encapsulated probiotics, they have to be recovered or released from the encapsulating matrix before they can be diluted and plated out on appropriate media (Champagne et al 2010). A number of methods have been used for release of encapsulated bacteria from different encapsulation matrices.

Sultana et al (2000) examined survival of probiotic bacteria encapsulated with alginate starch after suspending the microcapsules in phosphate buffer and homogenization in a stomacher for $30 \mathrm{~min}$. Chandramouli et al (2004) assessed viability of Lactobacillus spp. after suspending the capsules in phosphate buffer followed with gentle shaking at room temperature. Bifidobacterium adolescentis $15703 \mathrm{~T}$ was released from non-coated and alginatecoated gelatin microspheres using a Polytron homogenizer and tempered phosphate buffer for coated and non-coated microspheres, respectively (Annan et al 2008). Ma et al (2008) released bacteriophage Felix 01 from the encapsulating chitosan-alginate microspheres in vitro, by adding the microspheres to prewarmed simulated intestinal fluid (SIF) followed by incubation at $37^{\circ} \mathrm{C}$ with shaking at $100 \mathrm{rpm}$. Xiaoyan and Xiguang (2009) investigated the in vitro release behaviour of alginate and gelatin encapsulated lactic acid bacteria by subsequent addition and incubation of the microcapsules in simulated gastric fluid (SGF) (pH 1.2) and SIF (pH 7.4). Picot and Lacroix (2004) tested the survival of bifidobacteria encapsulated in whey protein-based spray dried microcapsules rehydrated in peptone buffered water followed by grinding in a roller-type jar mill for $1 \mathrm{~h}$ at room temperature. Recently, Champagne et al (2010) indicated that high-shear homogenization during rehydration is critical for viable count analysis of spray-coated microencapsulated cultures or else numbers will be underestimated. 
Since the compositions of the encapsulation matrices differ, it means that efficient release of the bacteria will also differ for the matrices in terms of the medium and the method used. Encapsulation of probiotics in an interpolymer complex matrix produces unique properties of the matrix as this method is different to all of the methods described above. As with all the other encapsulation methods, it is of crucial importance that the encapsulated bacteria be released from the PVP:PVAc-CA interpolymer complex matrix in order to establish how well the method preserves viability of the cultures. An appropriate release method should release the maximum number of bacteria without changing the composition or viability of bacteria in order to give the most correct estimation of the effectiveness of the particular encapsulation method. It is not known which release method will result in release of most of the bacteria encapsulated within the PVP:PVAc-CA matrix. Thus, the most suitable release method for bacteria encapsulated in a PVP:PVAc-CA interpolymer complex formed in super critical carbon dioxide $\left(\mathrm{scCO}_{2}\right)$ is yet to be established. It is also preferred that the microparticles encapsulating probiotics be small to minimize changes in the properties of the foods into which they are incorporated (Doleyres and Lacroix 2005; Picot and Lacroix 2003). The aim of this study was to evaluate three methods, namely, incubation in simulated intestinal fluid (SIF), homogenization using a stomacher and sonication, for release of encapsulated bifidobacteria from this matrix, and assessing viability using plate counts technique. Furthermore, SEM was used to investigate the effects of grinding on the morphological properties of the microparticles.

\section{Materials and Methods}

\section{Bacteria}

The lyophilized preparation of Bifidobacterium longum Bb46 was purchased from CHR-Hansen, Denmark. The bacteria were used in this powder form in encapsulation. 


\section{Encapsulation of bacteria}

The lyophilized B. longum Bb46 cells were encapsulated in the normal interpolymer complex matrix prepared in supercritical carbon dioxide using the Particles from Gas-Saturated Solution (PGSS) system, as described previously (Moolman et al 2006), without modification. Briefly, the lyophilized bacteria, Vinyl acetate-crotonic acid copolymer (VA-CA) (Vinnapas C305, mass-average molar mass 45 000g/mol, Wacker) and the dried Poly (vinylpyrrolidone) (PVP) (Kollidon 12PF, mass-average molar mass $2000-3000 \mathrm{~g} / \mathrm{mol}$, BASF) were mixed. The powder blend was immediately transferred to the pre-heated 11 reaction chamber. The chamber was then sealed, flushed and pressurized with sterile filtered $\mathrm{CO}_{2}(99.995 \%$ purity, Air Products) up to a pressure of 300bar, with the temperature controlled at $40^{\circ} \mathrm{C}$. The material was left to equilibrate for $2 \mathrm{~h}$ with intermittent stirring, after which the liquefied product was sprayed through a $500 \mu \mathrm{m}$ capillary with length $50 \mathrm{~mm}$, into a 101 expansion chamber that was pressure-controlled at 15 bar (gauge).

\section{Scanning Electron Microscopy (SEM)}

A portion of the PVP:PVAc-CA microparticles harvested from both the reactor chamber and collection chamber was milled once by grinding in a coffee grinder for 30s to further reduce their particle size. Samples (Collection chamber product, milled Collection chamber product, Reactor product fraction, milled Reactor product fraction) were then were fixed to a stainless steel stub on a double sided tape and then coated with gold. The samples were viewed under a JEOL 840 SEM.

\section{Preparation of Simulated Intestinal Fluid (SIF)}

For all release methods SIF was prepared according to US Pharmacopoeial (2005). Briefly, for 100ml SIF, $1.68 \mathrm{~g}$

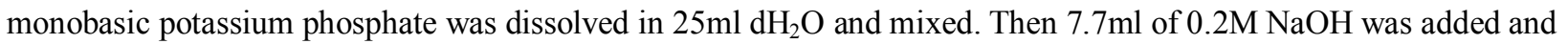

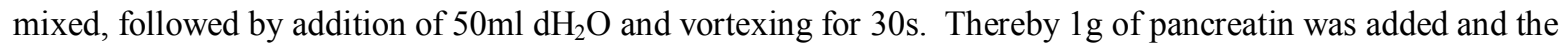
solution mixed again. The $\mathrm{pH}$ of the resulting solution was adjusted to $\mathrm{pH} 6.8$ using either $0.2 \mathrm{~N} \mathrm{NaOH}$ or $0.2 \mathrm{~N}$ 
$\mathrm{HCL}$ as required. The volume of the solution was made up to a final volume of $100 \mathrm{ml}$ with $\mathrm{dH}_{2} \mathrm{O}$. The solution was then filtered through a $0.45 \mu \mathrm{m}$ membrane.

\section{Release of bacteria from the encapsulating matrix}

Three methods were used for of release of bacteria from encapsulating matrix. The most commonly used method, incubation in SIF was compared to the stomacher and sonication.

\section{Incubation in SIF}

Encapsulated bacteria were released from the matrix according to Ma et al (2008), with minor modifications.

Samples of $1 \mathrm{~g}$ of encapsulated $B$. longum were added to $9 \mathrm{ml} \mathrm{SIF}$, followed by incubation at $37^{\circ} \mathrm{C}$ with shaking at a $200 \mathrm{rpm}$ for $6 \mathrm{~h}$.

\section{Homogenization in stomacher}

Homogenization of encapsulated bacteria in a stomacher was done according to Sultana et al (2000). Briefly, $1 \mathrm{~g}$ of encapsulated B. longum was suspended in $9 \mathrm{ml}$ of prewarmed $\operatorname{SIF}\left(37^{\circ} \mathrm{C}\right)$ in stomacher bags. The sample was then homogenized in a Lab-blender 400 stomacher for $30 \mathrm{~min}$.

\section{Sonication}

A modified method of Yang et al (2008) was used for the sonication of encapsulated B. longum. One gram of encapsulated bacteria was added to $9 \mathrm{ml}$ of prewarmed $\operatorname{SIF}\left(37^{\circ} \mathrm{C}\right)$ and sonicated for $1 \mathrm{~min}$ using a Cole-Palmer ultrasonic homogenizer (4710 series) at an output of 50\%. 


\section{Enumeration of viable bacteria}

Viable plate counts were carried out by a slightly modified method of Moolman et al (2006). One gram of product obtained from each release method was serially diluted (10-fold) up to $10^{-8}$ using Ringer's solution (pH7). A $100 \mu \mathrm{l}$ subsample of each dilution was pour-plated in triplicate onto MRS agar supplemented with $0.05 \%$ cysteine hydrochloride. The plates were incubated anaerobically at $37^{\circ} \mathrm{C}$ for $72 \mathrm{~h}$. The number of colonies between 30 and 300 were counted and used to calculate cfu/g.

\section{Statistical analysis}

The reported means are averages of triplicate counts. Data for the different release methods was compared using the $\mathrm{t}$-test for independent samples. Differences between means were considered to be significant when $\mathrm{p}<0.05$. StatSoft Statistica 9 software was used for analysis.

\section{Results and Discussion}

The most popular method for release of encapsulated bacteria is the suspension and incubation of encapsulated bacteria in a suitable release medium, most commonly simulated gastric or intestinal fluids, with or without mild shaking (mostly with shaking). The three release methods (homogenization by stomacher, sonication and incubation with shaking for $6 \mathrm{~h}$ ) were compared with each other according to colony-forming units per gram (cfu/g) of bacteria released from encapsulated product. The comparison was made taking into consideration the fact that a cfu may contain more than one cell, whereby a colony may represent more than one cell clumped together (Madigan and Martinko 2006).

Release of the encapsulated bacteria using the different methods was done three times, using a new batch of encapsulated material in each analysis. In all the trials performed, higher counts were observed when release of bacteria was undertaken using a stomacher, than when using the other two methods tested (Fig. 1). The viable counts obtained from the stomacher were on average significantly higher than the counts from the sonicator (trial 1: $\mathrm{p}=0.54$, trial 2: $\mathrm{p}=0.0 .00005$, trial 3: $\mathrm{p}=0.0007)$ and incubation (trial 1: $\mathrm{p}=0.00014$, trial 2: $\mathrm{p}=0.000003$, trial 3: 
$p=0.00024)$. The viable counts released using sonication as the release method were also significantly higher than when incubation in simulated intestinal fluid was used for release (trial 1: $p=0.00009$, trial 2: $p=0.0225$ and trial 3: $\mathrm{p}=0.0034$ ). The lowest counts (were obtained when using incubation in simulated intestinal fluids in all the three trials (Fig. 1). Interestingly, the viable counts obtained for all the three methods in the different trials were comparable to each other $(p>0.05)$. This indicated the repeatability of the release efficiency of the methods. The reported values are the means of triplicate counts.

On average, viable counts after release using stomacher was more than an order of magnitude greater than that for sonication and three orders of magnitude greater than that for $6 \mathrm{~h}$ incubation in SIF (Fig. 1). Homogenization with a stomacher was thus the most efficient in release of encapsulated bacteria giving the highest $\mathrm{cfu} / \mathrm{g}$ in each trial. The second best release method was sonication, while incubation in SIF for $6 \mathrm{~h}$ was the least efficient (Fig. 1).

Two of the methods used, incubation in SIF and homogenization in a stomacher, have been used successfully for release of bacteria from various encapsulating matrixes (Godward and Kailasapathy 2003; Thantsha et al. 2009), while sonication was used for disruption of cellular components such as biofilm (Nguyen et al. 2009). It was surprising however, that of the tested three methods, $6 \mathrm{~h}$ incubation was the least proficient method. The literature shows that suspension of encapsulated products in a suitable dissolution medium is the most popular method (Blum and Saltzman 2008; Chandramouli et al. 2004; Lyer, Kailasapathy and Peiris 2004; Ma et al. 2008; Sensoy et al. 2009; Thantsha et al. 2009; Xiaoyan and Xiguang 2009; Yang et al. 2008). The results indicate that, incubation of the encapsulated bacteria in simulated intestinal fluid for $6 \mathrm{~h}$ will result in the underestimation of the viable bacteria present in the matrix, due to incomplete release.

On the other hand, it makes sense for alternative methods tested to yield a better release of viable bacteria. During incubation in the appropriate medium, there is no force applied to assist release of bacteria from the encapsulating matrix. The other methods tested on the other hand, apply in addition to release of bacteria by dissolution and swelling of the matrix due to high $\mathrm{pH}$, some form of force that promotes the release of bacteria. For example, the sonicator makes use of high-frequency sound waves (Lo et al. 2002), whereas a stomacher simulates the beating and thumping of the human stomach to disrupt the polymer matrix (Sheu and Marshall 1993). These added effects of disrupting the polymer matrix not only aids in releasing bacteria, but accelerates the time in which bacteria are 
released. Instead of the polymer matrix naturally degrading over duration of 6 hours to gradually release bacteria, the sound waves and beating paddles artificially help break up the polymer matrix, just as the mechanical movements of the stomach speed up the digestion of food. These results adds to more evidence to support the findings of the recent study (Champagne et al. 2010) which indicated the significance of shear for efficient release of bacteria from the encapsulating matrix.

Thus, specifically with regards to release of the encapsulated bacteria from the PVP:PVAc-CA interpolymer complex matrix described by Moolman et al (2006), incubation method should not be used as it will results in incomplete release and lower viable counts. The use of this method will results in the underestimation of the protection efficiency of the interpolymer complex matrix. Instead, homogenization in a stomacher is recommended as it releases high numbers of the encapsulated bacteria.

\section{Scanning Electron Microscopy (SEM)}

Microparticles for food applications should be small. Microcapsules should on average have a diameter $<100 \mu \mathrm{m}$. This is to ensure their stability, easy handling and to minimize undesirable organoleptic qualities when they are incorporated into foods (Doleyres and Lacroix 2005; Picot and Lacroix 2003). SEM was used to investigate whether the particle size of the PVP:PVAc-CA interpolymer complex microparticles encapsulating bifidobacteria can be reduced further by grinding of the encapsulated product, without production of negative effects on the particles, such as exposure of the encapsulated bacteria upon grinding. The SEM micrographs of the milled and non-milled microparticles are shown in Fig. 2. Both the microparticles obtained from the reactor collection chamber and from the reactor vessel were investigated, since it is possible to harvest the encapsulated microparticles from the two vessels. The possibility of harvesting the encapsulated product from the different compartments is made possible by the set-up of the encapsulating system as explained previously (Thantsha 2007). It can be observed that there were no differences on the external appearance of the milled and non-milled products. No bacteria were visible on the surfaces of all the products viewed. This indicated that grinding could be used to further reduce the size of the microparticles enclosing bacteria without exposing the encapsulated bacteria from the matrix.

Subsequent enumeration of viable bacteria released from the milled and non-milled reactor products also indicated 
that equal numbers of viable cells were released from the milled $\left(6.2 \times 10^{8} \mathrm{cfu} / \mathrm{g}\right)$ and non-milled $\left(5.8 \times 10^{8} \mathrm{cfu} / \mathrm{g}\right)$ products.

\section{Conclusions}

Homogenization using a stomacher is the efficient methods for release of the bacteria enclosed within a PVP:PVAcCA interpolymer complex matrix. Incubation in simulated intestinal fluid results in incomplete release of the bacteria and hence an underestimation of the viable counts. Reduction of the size of the PVP:PVAc-CA interpolymer complex microparticles can be achieved by grinding, without exposing the encapsulated bacteria.

\section{Acknowledgements}

The authors would like to thank the National Research Foundation of South Africa for funding of the project, the Laboratory for Microscopy and Microanalysis of the University of Pretoria for assistance with the SEM work and Prof. Teresa Coutinho for language editing.

\section{References}

Annan NT, Borza AD, Truelstrup Hansen L (2008). Encapsulation in alginate-coated gelatin microspheres improves survival of the probiotic Bifidobacterium adolescentis $15703 \mathrm{~T}$ during exposure to simulated gastrointestinal conditions. Food Res Int 41: 184-193

Blum JS, Saltzman WM (2008) High loading efficiency and tunable release of plasmid DNA encapsulated in submicron particles fabricated from PLGA conjugated with poly-L-lysine. J Contr Release 129: 66-72

Champagne CP, Yves R, Tompkins TA (2010) The determination of viable counts in probiotic cultures microencapsulated by spray-coating. Food Microbiol. doi:10.1016/j.fm.2010.07.017

Chandramouli V, Kailasapathy K, Peiris P, Jones M (2004) An improved method of microencapsulation and its evaluation to protect Lactobacillus spp. in simulated gastric conditions. J Microbiol Meth 56: 27-36 
Doleyres Y, Lacroix C (2005) Technologies with free and immobilized cells for probiotic bifidobacteria production and protection. Int Dairy J 15: 973-988

Godward G, Kailasapathy K (2003) Viability and survival of free, encapsulated and co-encapsulated probiotic bacteria in yoghurt. Milchwissenschaft 58: 396-399

Homayouni A, Azizi A, Ehsani MR, Yarmand MS, Razavi SH (2008) Effect of microencapsulation and resistant starch on the probiotic survival and sensory properties of synbiotic ice cream. Food Chem 111: 50-55

Krasaekoopt W, Bhandar B, Deeth H (2003). Evaluation of encapsulation techniques of probiotics for yoghurt: a review. Int Dairy J 13:3 -13

Lo P-R, Chou C-C, Yu R-C, Tsai Y-H (2002). Antimutagenic activity of several probiotic bifidobacteria against benzo[a]pyrene. J Biosci Bioeng 94:148-153

Lyer C, Kailasapathy K, Peiris P (2004) Evaluation of survival and release of encapsulated bacteria in ex vivo porcine gastrointestinal contents using a green fluorescent protein gene-labelled E.coli. Food Sci Technol 37: 639642

Ma Y, Huang X, Korenevsky A, Pacan JC, Sabour PM, Wang Q, Xu Y (2008). Microencapsulation of Bacteriophage Felix O1 into Chitosan-Alginate Microspheres for Oral Delivery. Appl Environ Microb 74: 47994805

Madigan MT, Martinko JM, (2006) Brock Biology of Microorganisms, Pearson Prentice Hall, USA

Moolman FS, Labuschagne PW, Rolfes H, Thantsha MS, van der Merwe TL, Cloete TE (2006) Encapsulating probiotics with an interpolymer complex in supercritical carbon dioxide. S Afr J Sci 102: 349-354 
Nguyen TMP, Lee KY, Zhou W (2009) Stimulating fermentative activities of bifidobacteria in milk by high intensity ultrasound. Int Dairy J 19: 410-416

Picot A, Lacroix C (2003). Effects of micronization on viability and thermotolerance of probiotic freeze-dried cultures. Int Dairy J 13: 455-462

Picot A, Lacroix C (2004) Encapsulation of bifidobacteria in whey protein-based microcapsules and survival in simulated gastrointestinal conditions and in yoghurt. Int Dairy J 14: 505-515

Sensoy D, Cevher E, Özdamar A, Sarici A, Yilmaz M, Bergişadi N (2009) Bioadhesive sulfacetamide sodium microspheres: Evaluation of their effectiveness in the treatment of bacterial keratitis caused by Staphylococcus aureus and Pseudomonas aeruginosa in a rabbit model. Eur J Pharm Biopharm 72: 487-495

Sheu TY, Marshall RT (1993) Micro-encapsulation of Lactobacilli in calcium alginate gels. J Food Sci 54: 557-561

Sultana K, Arumugaswamy R, Godward G, Peiris P, Reynolds N, Kailasapathy K ( 2000) Encapsulation of probiotic bacteria with alginate-starch and evaluation of survival in simulated gastrointestinal conditions and in yoghurt. Int J Food Microbiol 62: 47-55

Thantsha MS (2007) Cell immobilization techniques for the preservation of probiotics. Dissertation, University of Pretoria.

Thantsha MS, Cloete TE, Moolman FS, Labuschagne PW (2009) Supercritical carbon dioxide interpolymer complexes improve survival of B. longum Bb-46 in simulated gastrointestinal fluids. Int J Food Microbiol 129: 8892

United States Pharmacopeial Convention (2005). United States Pharmacopeia, 25 ${ }^{\text {th }}$ edn, Webcom, Toronto 
Xiaoyan LI, Xiguang C (2009) Drying of Micro-Encapsulated Lactic Acid Bacteria Effects of Trehalose and Immobilization on Cell Survival and Release Properties. J Ocean Univ China 8: 39-44

Yang X, Chena H, Gaoa F, Wang Y, Zhang H, Zhang O, Liu L (2008) Self-aggregated nanoparticles from methoxy poly(ethylene glycol)-modified chitosan: Synthesis; characterization; aggregation and methotrexate release in vitro. Colloid Surface B 61: 125-131

\section{Figure captions}

Fig. 1 Average counts of viable bacteria released from the PVP:PVAc-CA interpolymer complex microparticles using the different methods tested

Fig. 2 SEM micrographs of non-milled and milled microparticles harvested from the reactor and collection chamber. a: non-milled product from product chamber, b: milled product from product chamber, c: non-milled product from the reactor, d: milled product from the reactor 
Fig. 1

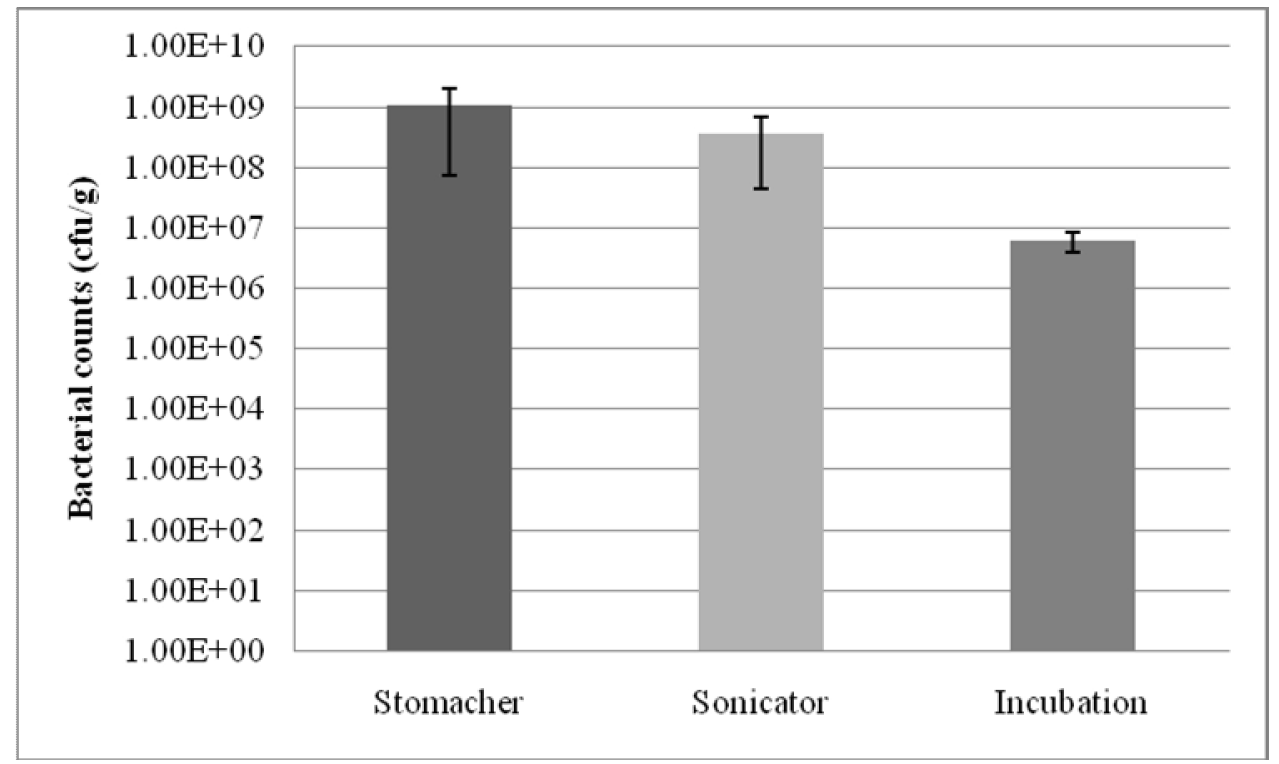


Fig. 2

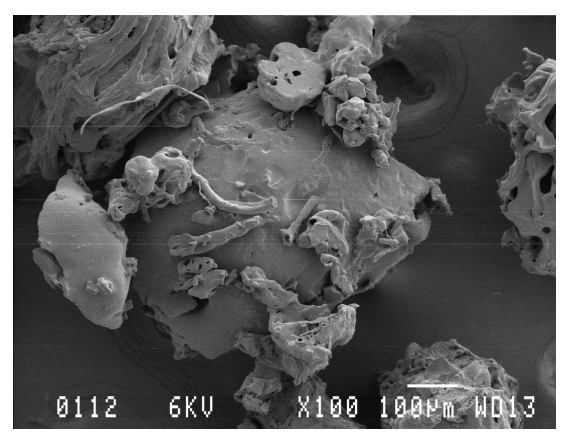

Fig. 2a

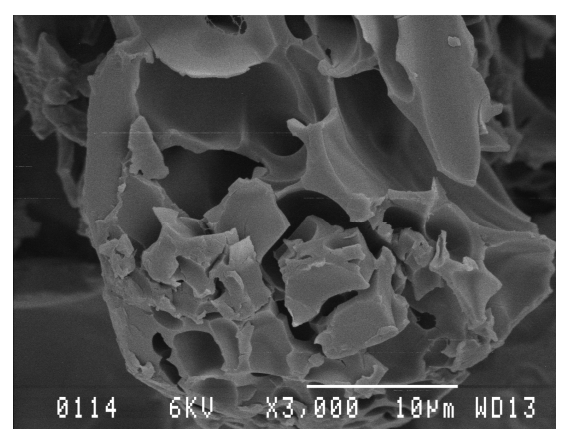

Fig. 2b

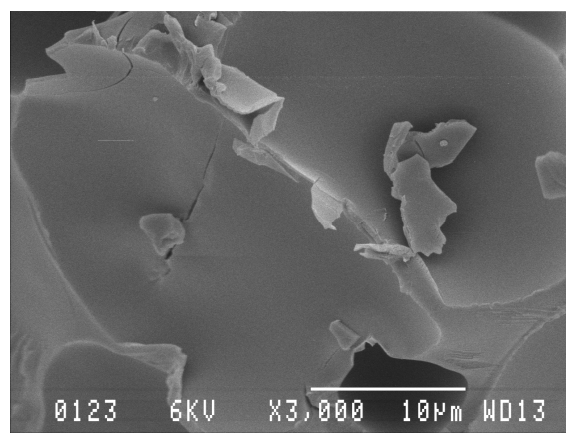

Fig. 2c

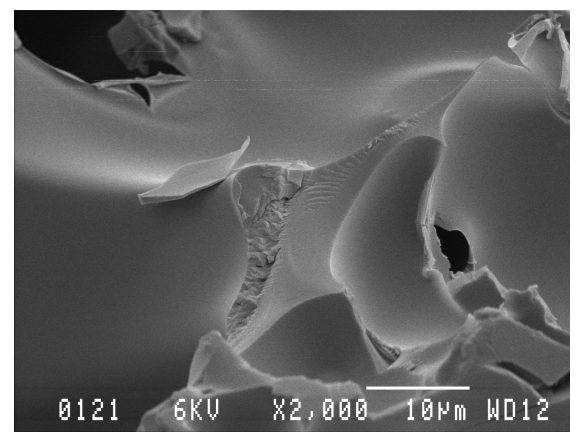

Fig. $2 d$ 